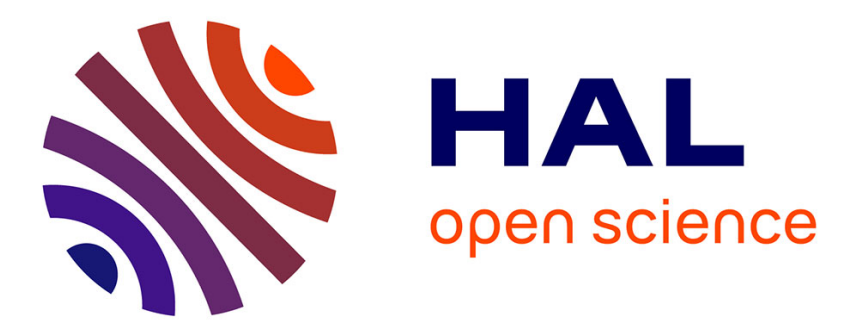

\title{
Nucleation of Martensite in CuZnAl Alloys as Investigated by Young's Modulus and Acoustic Emission Measurements
}

\author{
B. Coluzzi, A. Biscarini, S. Piazza, F. Mazzolai
}

\section{- To cite this version:}

B. Coluzzi, A. Biscarini, S. Piazza, F. Mazzolai. Nucleation of Martensite in CuZnAl Alloys as Investigated by Young's Modulus and Acoustic Emission Measurements. Journal de Physique IV Proceedings, 1996, 06 (C8), pp.C8-397-C8-400. 10.1051/jp4:1996885 • jpa-00254696

\author{
HAL Id: jpa-00254696 \\ https://hal.science/jpa-00254696
}

Submitted on 1 Jan 1996

HAL is a multi-disciplinary open access archive for the deposit and dissemination of scientific research documents, whether they are published or not. The documents may come from teaching and research institutions in France or abroad, or from public or private research centers.
L'archive ouverte pluridisciplinaire HAL, est destinée au dépôt et à la diffusion de documents scientifiques de niveau recherche, publiés ou non, émanant des établissements d'enseignement et de recherche français ou étrangers, des laboratoires publics ou privés. 


\title{
Nucleation of Martensite in CuZnAl Alloys as Investigated by Young's Modulus and Acoustic Emission Measurements
}

\author{
B. Coluzzi, A. Biscarini, S. Piazza and F.M. Mazzolai \\ Phys. Department, University of Perugia, Perugia, Italy
}

\begin{abstract}
Young's modulus (E) has been measured during cooling/heating cycles carried out between a fixed upper temperature $T_{2}\left(T_{2}=340 \mathrm{~K}\right)$ and a gradually decreasing lower temperature $T_{1}\left(T_{1}=320,310,300,290,285,281\right.$ and $279.5 \mathrm{~K}$ ). The $\mathrm{E}(\mathrm{T})$ curves show closed thermal hysteretic loops, which are needle-like for $\mathrm{T}_{1}>\mathrm{Ms}$ while they assume a downward bent shape for $T_{1}<M s$. The occurrence of thermal bysteresis in the cooling/heating $E(T)$ curves is interpreted as evidence of the formation, far above Ms, of static martensite embryos, which are stabilized by preexisting lattice defects. The formation, on cooling, and the delayed disappearance, on heating, of these static embryos is believed to be responsible for the needle shaped E(T) loops. Acoustic emission is found to occur only during the heating stages of partial thermal cycles carried out above Ms, suggesting that only the disappearance of a stabilized embryo is associated with an abrupt release of the stored energy.
\end{abstract}

\section{INTRODUCTION}

Many different aspects of martensitic transformation (MT) have attracted attention during the past decades, among these are pre-transitional [1-6] and nucleation/growth phenomena [7-12]. By virtue of the considerable amount of experimental [7-8] and theoretical [9-12] work carried out so far, it is now generally accepted that MT is initiated by heterogeneous nucleation, that is, nucleation triggered by localized strain fields associated with pre-existing lattice defects. It is also well established by now that precursor effects, such as softening of the C' shear elastic constant, usually accompany weak first order MT. Although pre-martensitic effects have not been revealed by NMR experiments [13], nonetheless, $\mathrm{CuZnAl}$ alloys exhibit substantial softening of the $\mathrm{C}^{\prime}$ shear elastic constant, as well as strong anharmonic behavior $[14,15]$. In this same series of alloys synchrotron $x$-ray topography has been able to reveal heterogeneous nucleation followed by unlimited growth of martensite at sub-grain boundaries and only in the close vicinity of $M_{s}[8]$. No evidence of the formation of static embryos above $M_{s}$ seems to have been provided so far.

The main aim of the present work has been that of studying pre-martensitic phenomena in $\mathrm{CuZnAl}$ alloys, far above $\mathrm{M}_{\mathrm{s}}$, by accurate Young's modulus ( $\mathrm{E}$ ), acoustic emission (AE) and differential scanning calorimetry (DSC) measurements. In the present paper results regarding Young's modulus and $\mathrm{AE}$ are presented and discussed.

\section{EXPERIMENTAL}

The atomic composition of the alloy used in the present work was $67.83 \mathrm{Cu}, 19.03 \mathrm{Zn}$ and $13.4 \mathrm{Al}$. After melting, the material was homogenized at $1073 \mathrm{~K}$ for about $4 \times 10^{4} \mathrm{~s}$, then machined to the form of rectangular bars of dimensions $2 \times 5 \times 50 \mathrm{~mm}^{3}$. Prior to any measurement, the samples were treated at 1050 $\mathrm{K}$ for $1200 \mathrm{~s}$, quenched into boiling water in the $\beta$ phase and then stored at room temperature for several months. This sequence of thermal treatments guarantees that vacancies are at equilibrium. The Young's modulus was derived from the resonant frequency, which at room temperature was about $2720 \mathrm{~Hz}$. The experiments were performed in vacuo at cooling/heating rates of about $10^{-1} \mathrm{~K} / \mathrm{s}$. Measurements of $\mathrm{AE}$ were carried out on a sample that had been cut from the same bar as that used for the elastic modulus observations, prior to any experiment. 


\section{RESULTS}

From Young's modulus, DSC and AE data taken during complete thermal cycles of the material in the same conditions the mean characteristic temperatures for the direct and reverse transition are the following : $M_{s}=280 \mathrm{~K}, M_{\mathrm{f}}=271 \mathrm{~K}, \mathrm{~A}_{\mathrm{s}}=282 \mathrm{~K}, \mathrm{~A}_{\mathrm{f}}=288 \mathrm{~K}$

Figures 1a-1d show data taken during thermal cycles carried out in sequence between a fixed upper temperature $T_{1}\left(T_{1}=350 \mathrm{~K}\right)$ and a gradually decreasing lower temperature $T_{2}\left(T_{2}=320,310,300\right.$, $290,285,281$ and $279.5 \mathrm{~K}$ ). As can be seen in fig. la the cooling and heating stages of the cycle perfectly overlap one another indicating full absence of any nucleation process of the martensitic phase above 320 $\mathrm{K}$. The temperature dependence of the Young's modulus only slightly departs from linearity, the temperature coefficient $d E / d T$ becoming gradually less negative with decreasing $T$. With cycles extending further down in temperature, cooling and heating curves do not match anymore and tend to display increasingly wider thermal hysteretic loops. For $T_{2} \geq 290 \mathrm{~K}$ these loops are needle like, while they assume a curved shape for lower values of $\mathrm{T}_{2}$.

An interesting aspect of all the Young's modulus cooling/heating curves is the fact that they tend to become closed loops provided the sample is heated up to sufficiently high temperatures (typically 340 $\mathrm{K}$ ) and that the cooling branches are retraced during successive cycles. This means that whichever is the source of the hysteresis this source disappears on heating above $340 \mathrm{~K}$.
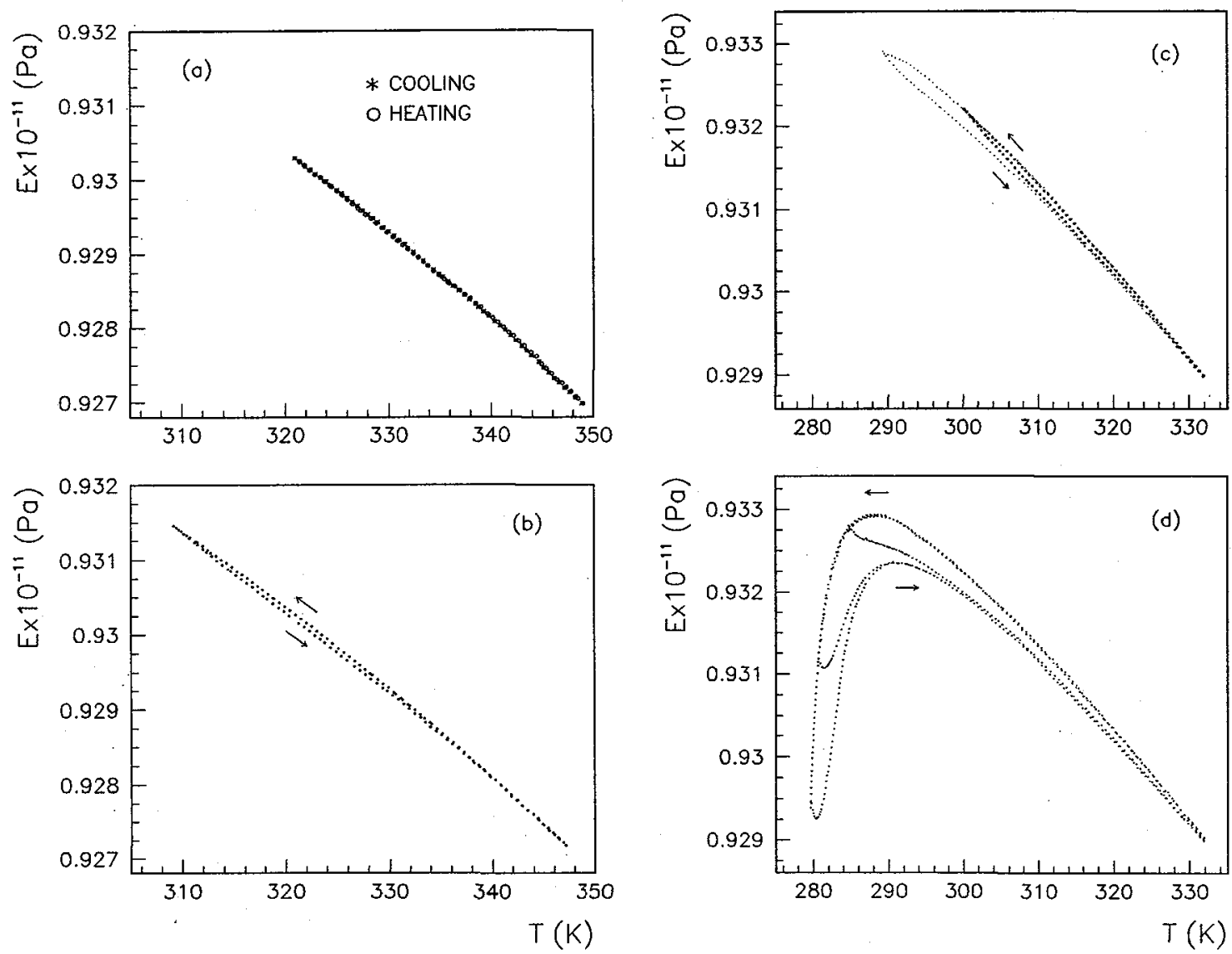

Figure 1: Young's modulus as measured during thermal cycles between a fixed higher temperature $\mathrm{T}_{1}=350 \mathrm{~K}$ and a gradually decreasing lower temperature $\mathrm{T}_{2}=320 \mathrm{~K}$ (a), $310 \mathrm{~K}$ (b), 300, 290 K (c) and $285,281,279.5 \mathrm{~K}$ (d) 
Acoustic emission events recorded during a complete heating/cooling cycle are reported in fig. 2 , where is also shown the noise level as deduced from a dummy sample. As can be seen in this figure, the number of counts is about two times higher for the reverse than the direct transition, in agreement with other experiments [16]. Fig 3 shows AE data taken during partial cycles carried out between 290 and 330 $\mathrm{K}$ and 300 and $330 \mathrm{~K}$ that is, at temperatures higher than $\mathrm{M}_{\mathrm{s}}$. As can be seen, during cooling the emission is at noise level, while during heating it is about 20 times higher. This observation, which has also been observed in three additional partial cooling/heating cycles, is in agreement with results by [16], who also measured

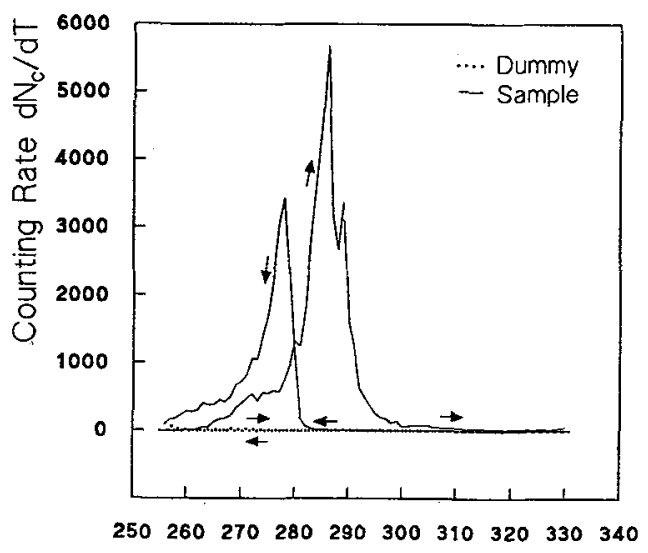

$T(K)$

Figure 2: AE counting rate as measured in a sample and in a dummy sample during a thermal cycles between 255 and $330 \mathrm{~K}$

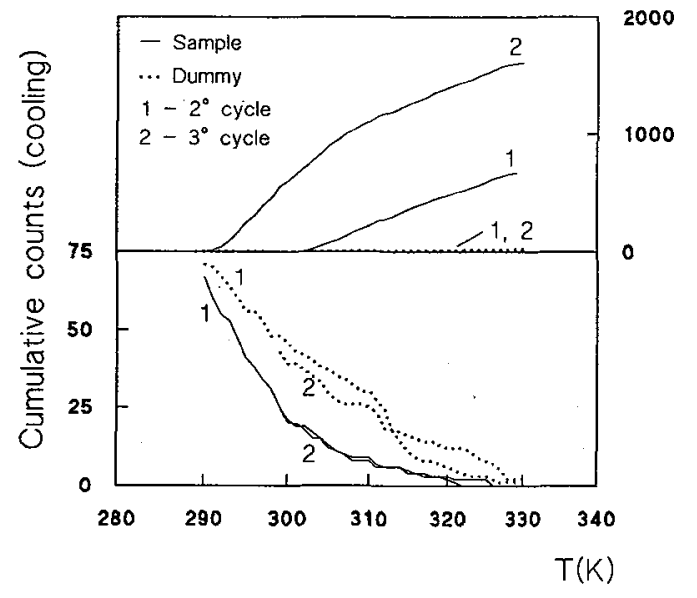

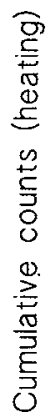

Figure 3: $\mathrm{AE}$ cumulative counts as measured in a sample and a dummy sample during thermal cycles at $\mathrm{T}>\mathrm{M}_{\mathbf{s}}(281 \mathrm{~K})$

$\mathrm{AE}$ at temperatures higher than $\mathrm{M}_{\mathrm{s}}$ during the heating portion of thermal cycles carried out over narrow temperature ranges. Optical microscopy did not reveal the occurrence of any martensitic platelet during these cycles.

\section{DISCUSSION}

The bulk of the experimental evidence presented in this paper clearly shows that some sort of martensite nucleation starts to occur far above $M_{3}$. It is unlikely that the hysteretic effects observed in the Young's modulus are associated with the formation of fully developed martensite platelets at high temperature as a consequence of chemical inhomogeneity of the material. As a matter of fact, the temperature ranges of both the direct and reverse transitions are narrow and well defined. Early formation of martensite platelets at the external surface of the sample can be ruled out as a source of AE above $\mathrm{M}_{\mathrm{s}}$, since optical microscopy did not succeed in detecting them [16]. Also the absence of AE on cooling and of anomalies in the heat flow (on cooling and on heating) [17], strongly support the idea that martensite platelets are not formed far above $M_{s}$. This conclusion is also in accordance with synchrotron $x$-ray topography observations, which provide evidence of martensite platelets just at temperatures close to $M_{s}$.

On the basis of these considerations the observed elastic hysteresis can more reasonably be attributed to the formation of embryos of subcritical size stabilized by the strain field of strong lattice defects [18]. The situation is illustrated by fig.4, taken from [18], where the work for the formation of a martensite embryo interacting with a strong defect is schematically plotted as a function of the embryo size ( $r$ ), for two different levels $\Delta \mathrm{g}_{1}$ and $\Delta \mathrm{g}_{2}\left(\Delta \mathrm{g}_{1}<\Delta \mathrm{g}_{2}\right)$ of the driving force of the transition, that is, for two different temperatures $T_{1}$ and $T_{2}\left(T_{1}>T_{2}\right)$. At temperature $T_{1}$ an embryo of size $r_{e}$ smaller than the critical size $r^{*}$ is stabilized by the insurmountable energy barrier $\Delta W^{*}$. This embryo will start growing 
only at temperatures $T \leq T_{1}$ where $\Delta W^{*}$ becomes surmountable by thermal activation. For $T \leq T 2$ the interaction with the lattice defect leads to barrierless nucleation, immediately followed by unlimited growth, which will
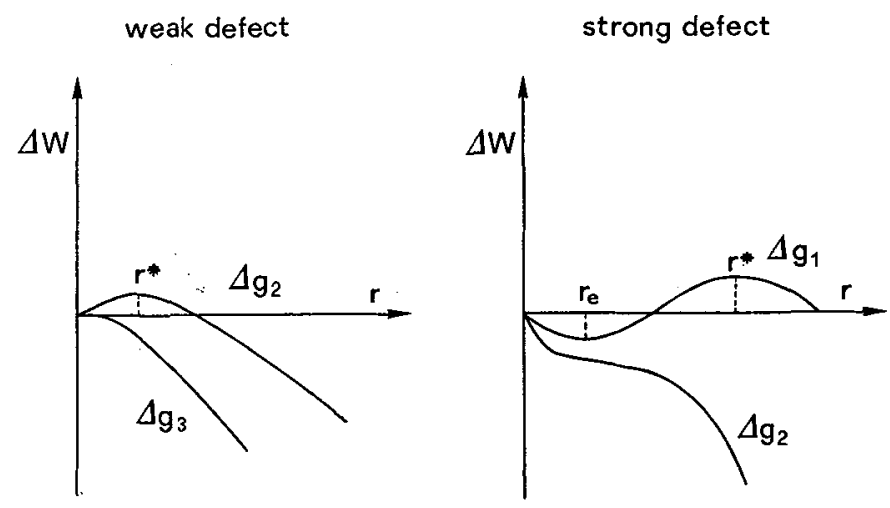

Figure 4: Schematic plots of the energy $(\Delta W)$ vs. size $r$ of a martensitic nucleus formed near a weak and strong defect for different levels of the driving force $\Delta G$ (from 18)

give rise to an autocatalytic nucleation process. The actual' features of embryo stabilization depend on the detailed structure of the nucleating defect and are expected not to be identifiable on the basis of the present results.

\section{ACKNOWLEDGMENTS}

The authors gratefully acknowledge financial support form Progetto Nazionale Materiali Speciali per Tecnologie Avanzate.

\section{References}

1 C.Zener,Phys.Rev. 71 (1947) 846

2 L.R.Testardi and T.B.Bateman,Phys.Rev.154 (1967) 402

3 N.Rusovic and H. Varlimont,Phys.Stat.Sol.(a) 44 (1977) 609

4 G.Guenin and P.F.Gobin,Met. Trans. 13A (1982) 1127

5 B.X.Shapiro,B.X.Yang,Y.Noda,L.E.Tanner and Scryvers,Phys.Rev.B44 (1991) 9301

6 L.E.Tanner,Phil.Mag.14 (1966) 111

7 I.W.Chen and Y.H.Chiao,Acta Metall.33 (1985) 1827

8 C.Jourdan,J.GastaldiG.S.Grange S.Belkahla and G.Guenin Acta Metall.Mater.43 (1995) 4227

9 P.C. Clapp,Phys.Stat.Sol.(b) 57 (1973) 561

10 G.B.Olson and M.Cohen,Met. Trans.7A (1976) 1897

11 M.Suezawa and H.E.Cook,Acta Metall. 28 (1980) 423

12 A.L. Roitburd, Sov.Phys.Dokl.26 (1981) 92

13 S.Rubini,C.Dimitropolous,R.Gotthardt and F.Borsa,phys.Rev.B44 (1991) 2019

14 B.Coluzzi,A.Biscarini and F.M.Mazzolai,ICOMAT-92,Institute of Adv.Studies,Monterey, 1993

15 B.Coluzzi,A.Biscarini and F.M.Mazzolai,J.Alloys and Comp.211-212 (1994) 190

16 D.Maeder,P.Ryser,B.Sanderson,A.Sillou and A.Steiner,J.de Physique 44 (1983) C9-253

17 B.Coluzzi,A.Biscarini and F.M.Mazzolai,G.Airoldi and G.Riva,To be published

18 G.B.Olson and A.L. Roitburd, in:Martensite ed.by G.B.Olson and W.S.Cohen,ASM,1992 